\title{
Yet Another Role for Job Satisfaction and Work Motivation - Enabler of Knowledge Creation and Knowledge Sharing
}

\author{
Celina Pascoe \\ University of Canberra, \\ $A C T$, Australia
}

cxp@comedu.canberra.edu.au

\author{
Irena M Ali \\ Department of Defence, \\ Canberra, Australia \\ irena.ali@dsto.defence.gov.aw
}

\author{
Leoni Warne \\ Department of Defence, \\ Canberra, Australia
}

\section{Abstract}

This paper describes a continuing study which uses a mixture of qualitative and quantitative research methods to identify factors which facilitate organizational and other types of collaborative learning. In this study, such learning is termed 'social learning', and refers to those factors which enable the sharing of knowledge and practice, and which foster generative learning. This paper's specific focus is on the roles played by job satisfaction and morale in collaborative learning.

The study to date has undertaken research in three settings: a tactical headquarters, a single service strategic headquarters; and a joint services strategic headquarters. The study's long term aim is to develop architectures to support the development of organizational and information systems that enhance organizational learning and facilitate knowledge management.

Keywords: knowledge management, organisational learning, organizational studies, job satisfaction, motivation, defence studies, architecture

\section{Introduction and Research Context}

The role of job satisfaction in organisational performance has been discussed since the 1930s. However, in today's business climate of continuous changes and uncertainty, the importance of job satisfaction to organisational performance needs to be seen from a new perspective. Organizations need to respond creatively to market forces, and so organizational knowledge, and its effective incorporation into the organization's practice, has become a critical issue for business activity. Additionally, employees no longer remain in one organization for the majority of their working lives, and so organizational knowledge literally 'walks out the door' into that of competing organizations. Many organizations address these issues by investing heavily in information technology, but often without substantial success. One reason for this lack of success is too little regard for the ways in which people in organizations go about creating, acquiring, sharing, and making use of information and knowledge (Bednar 2000; Davenport 1994; Vandeville 2000). Another reason is a lack of understanding of the elements that foster the creation, sharing, and management of knowledge within and between organisational groups. One of these elements, which is of particular importance, is employees' motivation to come up with new and better ways of working, their willingness to voice and discuss innovative ideas, and their willingness, generally, to share information

Material published as part of these proceedings, either on-line or in print, is copyrighted by Informing Science. Permission to make digital or paper copy of part or all of these works for personal or classroom use is granted without fee provided that the copies are not made or distributed for profit or commercial advantage AND that copies 1) bear this notice in full and 2) give the full citation on the first page. It is permissible to abstract these works so long as credit is given. To copy in all other cases or to republish or to post on a server or to redistribute to lists requires specific permission from the publisher at Publister@intommingscience.org and corporate knowledge with their organizational colleagues. This paper discusses how such motivation and willingness are associated with job satisfaction and morale.

The Enterprise Social Learning Architectures (ESLA) task is a four-year research study investigating, within the Australian Defence Organisation (ADO), the procedures that facilitate generative 
Yet Another Role for Job Satisfaction and Work Motivation

learning - learning that enhances the enterprise's ability to adjust to dynamic and unexpected situations and to react creatively to them. The term 'social' learning has been used to reflect that organisations, organisational units, and work groups are social clusters, and that learning therefore occurs in a social context. The study's long term aim is to develop architectures to support the development of organizational and information systems that enhance organizational learning and facilitate knowledge management. The study has undertaken research in three settings: a tactical headquarters, a joint services strategic headquarters, and most recently a single service strategic headquarters. At the Informing Science Conference of 2001, the ESLA team reported on progress to date and focussed on elements of workplace culture that foster generative learning within organisational teams. This year's paper updates the ESLA findings by reporting both qualitative and quantitative results from the single service strategic HQ, with specific emphasis on the role of employees' job satisfaction and morale on their motivation and willingness to share knowledge and voice their ideas.

There is a tightly coupled relationship between social learning and organisational learning because they both refer to learning occurring in social clusters. Tsang (1997) refers to three basic elements common to most definitions of organisational learning:

1. Cognition - gaining knowledge, insight and/or understanding

2. Change in actual behaviour - acting upon this in a way that introduces improved methods, procedures, processes, policies, or practices

3. Change in potential behaviour - acquiring a basis, or launch-pad, for introducing new policies, procedures, and practices to meet future needs.

It is this third element of organizational learning, the potential to change behaviour, that is of importance to the ESLA research because, inter alia, continual postings to different work situations require learning that enhances the ability to adjust and react creatively to dynamic and unexpected situations.

One definition of organisational learning that captures this third element is put forward by Nevis (1995):

"We define organizational learning as the capacity or processes within an organization to maintain or improve performance based on experience" (cited in Magun \& Newton, 1998). It is in this sense of the "capacity' to improve performance that job satisfaction and employee morale can facilitate generative learning. Richards \& Goh (1995, cited in Newton \& Magun, 2001) conducted an employee-based survey of organisational learning in both the private- and public- sector in Canada and has found that employee satisfaction increased with the organisational learning survey score. This poses a question of whether there is a recursive relationship between job satisfaction and morale, and levels of organisational learning?

\section{Research Methodology}

The ESLA team used both qualitative and quantitative methods to obtain data. Quantitative surveys were used in both joint service and single service strategic HQs. In both settings the total population was surveyed and the response rate in the joint HQ was $96.7 \%$ and in the single service HQ, $71 \%$.

The qualitative method involved ethnography in the form of fieldwork and observation of work in all of the settings. The qualitative methods were important because they provided a rich context for the social aspects of the process of learning. Observations were made of the work taking place in different settings, and where possible, directed questioning was used to clarify issues.

Extensive unstructured interviews were also undertaken with a sample of personnel from the joint and single service strategic HQ. A stratified sampling technique was used to ensure an adequate representation was achieved. The specific characteristics that were of interest were: branch and directorate (sub-branch) affiliation, gender, rank, whether military or civilian, work location, and duration of placement. The main advantage of this type of sampling was that it ensured that the relevant variables were represented. In total 
63 interviews were conducted, 15 in the joint service headquarters and 48 in a single service strategic headquarters.

All research data, therefore, was triangulated by methods of data collection, by researcher (a multidisciplinary team) and by each study's functional role (each study has taken place in different locations as well as in functionally different sections of the ADO).

\section{Findings}

The variety of the settings that have been studied and the consistency of study findings make it feasible to extrapolate the results to a wide range of organisations embarking on a path of organisational learning. The ESLA team has already widely disseminated its findings at national and international forums. It is the authors' contention that before we can build tools for the intelligent enterprise we need to optimize organizational culture to sustain organizational learning. The study findings are multilayered and have resulted in the following set of overarching values that facilitate effective social learning:

- Empowerment;

- Trust;

- Forgiveness (forgiving mistakes and facilitating knowledge construction on the basis of lessons learnt);

- Cultural cohesiveness;

- Commitment (which includes a mutual commitment and loyalty between the employee and the organization)

- Openness of the decision making process; and

- A culture of information sharing.

Discussion of the role of these overarching organizational values in nurturing learning processes and strategies can be found elsewhere (Ali et al, 2001).

Based on the research findings, the ESLA team has also identified five basic constructs that enable social learning: Organizational Culture, Job Satisfaction \& Morale, Knowledge Management, Team Building, and Professional Development of Individuals (see Figure 1). A sixth construct, Communication, has been referred to in earlier reports of the ESLA findings; however, communication processes are inherent rather than separate from the other social learning enablers and so have been incorporated into them.

The social learning constructs in Figure 1 overlap in order to represent the interrelationship between all the strategies and processes contributing to effective social learning.

Further details of these social learning constructs and the associated strategies and processes, and of the findings on the role of trust and organisational cultural elements in the social learning process, occur elsewhere (Ali, et al, 2000; Ali, et al. 2002; Pascoe, et al. 2002). 
Yet Another Role for Job Satisfaction and Work Motivation

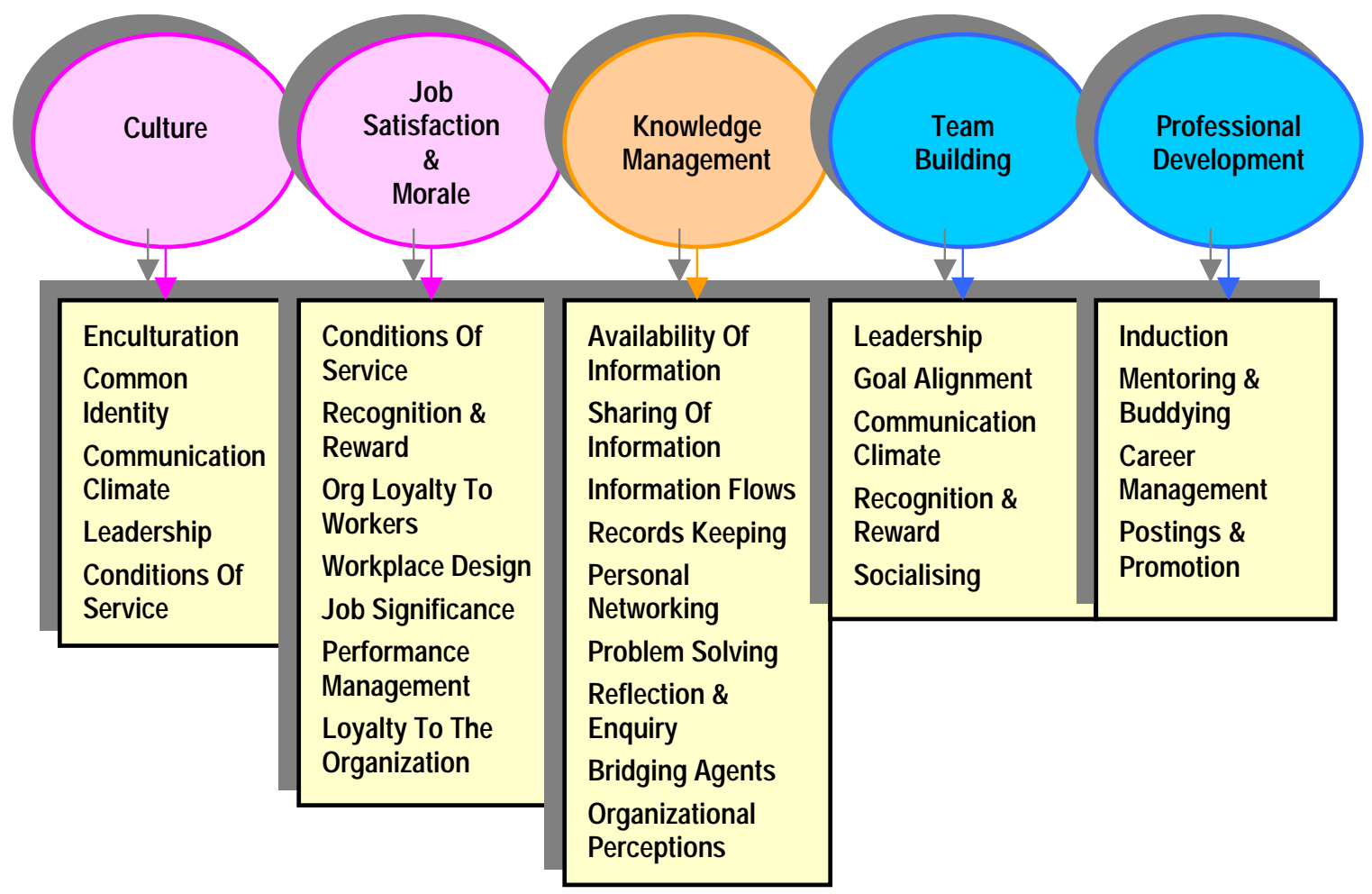

Figure 1 Constructs enabling social learning

\section{Study Findings in relation to Job Satisfaction and Morale}

This paper focuses on the social learning strategies and processes that have been categorised under the Job Satisfaction and Morale construct because our attitudes towards our jobs influence our motivation to perform well in them (Hackman \& Oldham,1980), and the authors propose that this in turn influences our motivation to come up with new and better ways of working, as well as our willingness to voice and discuss innovative ideas and, generally, to share information and corporate knowledge with our organizational colleagues.

The findings reported in this paper relate to the third setting of the ESLA study, a single service strategic HQ, in which seven social learning processes and strategies were identified that relate to Job Satisfaction and Morale. As can be seen from Figure 1 above, these are:

- Conditions of Service,

- Recognition \& Reward,

- Organizational Loyalty to Workers,

- Workplace Design,

- Job Significance,

- Performance Management, and

- Loyalty to the Organisation.

These seven elements of Job Satisfaction and Morale align with components of the Job Characteristics Model (Hackman \& Oldham, 1980) that are claimed to be necessary for job satisfaction and the motivation to perform one's job well. For instance, Conditions of Service, Recognition \& Reward, Organizational Loyalty to Workers, and Workplace Design all relate to one's satisfaction with the work context, or to use Hackman and Oldham's (1980) terms, "Job Context Satisfaction". Similarly, Job Significance 
(your own belief that your work is important and has value) and Performance Management relate to "Experienced Meaningfulness of Work" and "Knowledge of Results", respectively, both of which are posited as necessary psychological states for high levels of motivation to work well. Whilst there appears to be no direct relationship between Loyalty to the Organization and elements of the Job Characteristics Model, one's attitude to the organization for which they work would influence their motivation to work well.

\section{Conditions of Service}

Generally, the data indicates that there is a perception that the conditions of service and the implementation of certain associated policies and practices are having some negative impacts on how people view their work environment.

The interviews highlighted how social changes with regard to individuals' goals and aspirations are impacting on work expectations. An example is the difference in expectations between long serving personnel and new recruits (generation of baby boomers and generation X). Long serving members, until very recently, thought of their work in the Defence Forces as a long term career; however, new personnel view it as an opportunity to enjoy the work and the challenges the military offers, but not necessarily as a life long career. The changing role of the military from war fighting to that of the peacekeeping and humanitarian assistance has an impact on the conditions of service and ultimately on job satisfaction. The data clearly indicates that younger personnel now have much higher expectations of being able to balance their personal life with work commitments. Thus, many comments occurred in the interviews that related to 'family friendly policies' in the service, for example:

"I'd leave ... if that's what's necessary because I have to put my family first now."

"I don't think [this service] has found a method to address women who want to have families..."

"My partner and I have not lived in the same state since'95...it's just not a sacrifice I'm prepared to keep making."

The shrinking labour market available for recruiting new staff led to the 'civilianisation" of some military billets, the billets which were often perceived to be the 'jewels in the crown' as far as military postings are concerned. Although it was recognised that the civilians formed an important part of the service, there seemed to be some degree of resentment:

[There is] "the perception that civilians were taking over the organisation...a lot of things we used to do is now being taken over by civilians... We had people come in and weren't trained to the same level as the [service] people. It meant then the [uniformed] people had to take up the slack."

Two quality of work issues emerged from the interviews: having interesting and challenging work (which is discussed under the heading of job significance), and the change in the way things are manufactured and repaired. An example relating to the latter is:

"The technicians... are very much monkey see monkey do these days...he'll ...learn to replace boxes. That's his career."

This change in the way things are replaced rather than repaired has a significant impact on job design and it may be necessary to re-design other aspects of maintenance-type jobs to sustain interest and variety.

Due to the changing economic climate there were changes introduced to promotion and advancement policies. This has impacted heavily on officers' perceptions of conditions of service:

"I have a letter from the Chief of Defence Force (CDF) telling me that I can expect probably two jobs in rank and then it's up or out."...'I have no security of tenure here, whereas before I was promoted to this rank I probably did." 
Many interviewees indicated they had planned to stay until they were 55 years old, but that they now felt that this was not possible. Interestingly, this has been compounded by the policy of the service whereby some talented young people are being given fast track promotions, and by the perception that if you have not reached a particular rank by a certain age then you are wasting your time staying in the service.

With the downsizing policies that plague most government and private sector organisations, the culture to work long hours seems to be heavily entrenched. This occurs both at junior and senior ranks. The research data points to the general perception that junior staff will be told to go home, but that no-one tells the senior ranks to go home and not to work such long hours.

The quantitative survey canvassed opinions on having sufficient resources to do your work, and the workload. Sixty-two percent and $72 \%$, respectively, of respondents were satisfied with the level of resourcing and the workload, indicating that this factor is not adversely affecting Job Satisfaction and Morale.

\section{Recognition and Reward}

The lack of proper recognition for a job well done seems to be an endemic problem for many organisations (Mitchell, 2000). The research data indicates that the lack of recognition and extrinsic reward for one's work is mainly due to the system because rules and regulations largely prevent supervisors from offering "encouragement awards" (such as gift vouchers) in recognition of a job well done. Most interviewees talked about the use of promotion as a reward, but also emphasised that not everyone who is capable is going to be promoted because there are not enough positions available.

Interviewees also commented that the existing honours and awards system is complex. The research team was told that due to a heavy workload commendations are not written (only one or two people seem to be writing up $90 \%$ of the commendations), and as a consequence there are probably a large number of exceptional people who are missing out. Quotes typical of those about the honours and awards system are:

"The honours and awards system is quite a complex one but it's one of the most publicly and visibly recognised way of getting reward."

"Conspicuous service medals and the Australia Day Medals ...there's a general avoidance of people [in this HQ] getting those sort of things because it's then seen as being nepotistic, if the head shed [HQ] gets all the kudos."

There were also a number of comments about inadequate feedback:

"I've been here for three months and I don't get any feedback on the work that I've done...I presume it's been OK because they haven't come back to me and said "You're hopeless."

On the matter of intrinsic reward, typical comments were:

"It's been very rewarding personally, professionally, if not financially, but I've done a lot of really interesting things."

“...You get offered good opportunities because you're good doing that stuff and you're working hard.."

Such comments indicate that some have specifically joined the military because of intrinsic rewards such as a wide variety of jobs and opportunities.

\section{Organisational Loyalty to Workers}

The prevailing economic climate has led many organisations onto a path of implementing efficiency measures. Restructuring, frequent organisational changes and downsizing are the results of that. It is not 
surprising, therefore, that there is the perception that the organisation is less loyal to workers now than in the past as illustrated by the following comment:

"Well hang on, there ain't no loyalty here, and I'm busting my buns and have for the past 30 something year, always been a workaholic and always delivered $150 \%$."

The other aspect of organisational loyalty raised during interviews related to the contract of trust between leaders and staff being broken:

"[There is the] expectation that there's going to be more money put into people and the only place they can get that money from, because they can't go across to the government say 'we need more money“... The only way they can get it is out of operating costs."

"We keep saying that people are the backbone of [this service], but there is a general feeling out there that that is a platitude and we don't really live up to that."

\section{Loyalty to the Organisation}

According to Reichheld (2001) unless leaders of an organisation have built relationships on loyalty then nothing will keep staff and other stakeholders from jumping ship the instant a better opportunity comes along. This is likely to be reflected in the level of job satisfaction and staff retention rates, and involves staff being loyal to the organisation and the organisation being loyal to staff. Reichheld (2001) also states that true employee loyalty includes responsibility and accountability for building successful, mutually valuable relationships. Many of the interviewees considered themselves loyal to the service, were happy, and would stay with the service forever, if they could:

"I'm...sort of very proud to be wearing the uniform and I knew it was something that I wanted to do when I was in high school."

"I'm probably actually quite loyal to the organisation, shared objectives you know it would take a long period of not having a good time. It's not just a case of I didn't enjoy the last six months."

There were, however, some mixed messages from people who perceived themselves as extremely loyal to the service and yet they were leaving it:

'I'm leaving but I've actually really enjoyed it. It's the best place that I've worked with Defence...I'm really glad I worked here and I've got this loyalty to the service, which is making me sad to leave."

"there is a simmering air of discontentment and unhappiness and there's also this underpinning loyalty and love for the service."

In the quantitative survey only $15 \%$ of respondents indicated that they would not consider a career outside Defence. This could lead to a serious problem should those remaining $85 \%$ employees act upon it and leave the Department.

Despite the mixed messages concerning loyalty to the service, and despite the fact that staff still indicated they are leaving, there is a clear sense of loyalty to the service.

\section{Workplace design}

The physical design of a workplace impacts on the behaviours that occur in that space. Fifty-nine percent of respondents to the quantitative survey found the work environment too noisy, and only $45 \%$ indicated they could work effectively in the open plan environment. From the interview data it became apparent that the preferred solution to this was to book a quiet conference room and work there. 
Yet Another Role for Job Satisfaction and Work Motivation

Interestingly, some interviewees' comments indicated they favoured an open plan environment, and that common identity, morale and communication had been enhanced due to the collocation of staff:

"You can just pull up a chair and talk about something"

"It really promotes a team, and what it does promote is the transfer of knowledge."

\section{Job Significance}

Job significance is the extent to which one feels his or her work is significant, or is something that 'counts', and if one sees their job as trivial they are unlikely to experience it as meaningful. In turn, they are unlikely to develop a high level of job satisfaction or work motivation (Hackman \& Oldham, 1980). Regardless of industry or organisation, lack of tangible and significant outcomes from work can lead to workers being less willing to engage in generative learning.

Most of the interviewees talked about the importance of feeling they are making a contribution and that their work is having an effect. Some indicated that working at the HQ has given them a clearer picture of what the service does and how they contribute to that, for example:

"It's the first job I've ever had where I can make a big difference, and I love it."

"I really enjoyed it because I felt I was actually contributing something."

"I'm very pleased to be going back to something where...I think I can make a contribution because I struggled to find a way to really make a contribution."

"Service to our nation is one of the greatest things you can ever do and the simple satisfaction of something like Timor, of something like the Gulf, of actually getting out there and doing what you are trained to do is remarkable."

Others talked about a lack of challenge and job significance as a reason for leaving:

"More administration, it's a day-to-day task that doesn't contribute to the bigger goal... doesn't have a big impact on any projects whatever."

The research data clearly points to lack of job significance as a main reason for those who leave the service.

\section{Performance Management}

Assessment, reporting and performance management form a significant part of the overall management of military personnel throughout their careers. Issues raised in relation to performance management of individuals are indicated by the following comments:

“...Evaluation of personnel and reports were not handed in on time and as a result some people missed [out] on advancement."

“...It doesn't say anything about, you know, congratulations, well done, or how valued you are to the organisation. What it says is that "Now that you're here, perform or you're out."

Individuals identified the following as important in their performance management: realistic goals, trust, making sure your performance is fully recorded, and the linking of the financial and performance systems. 


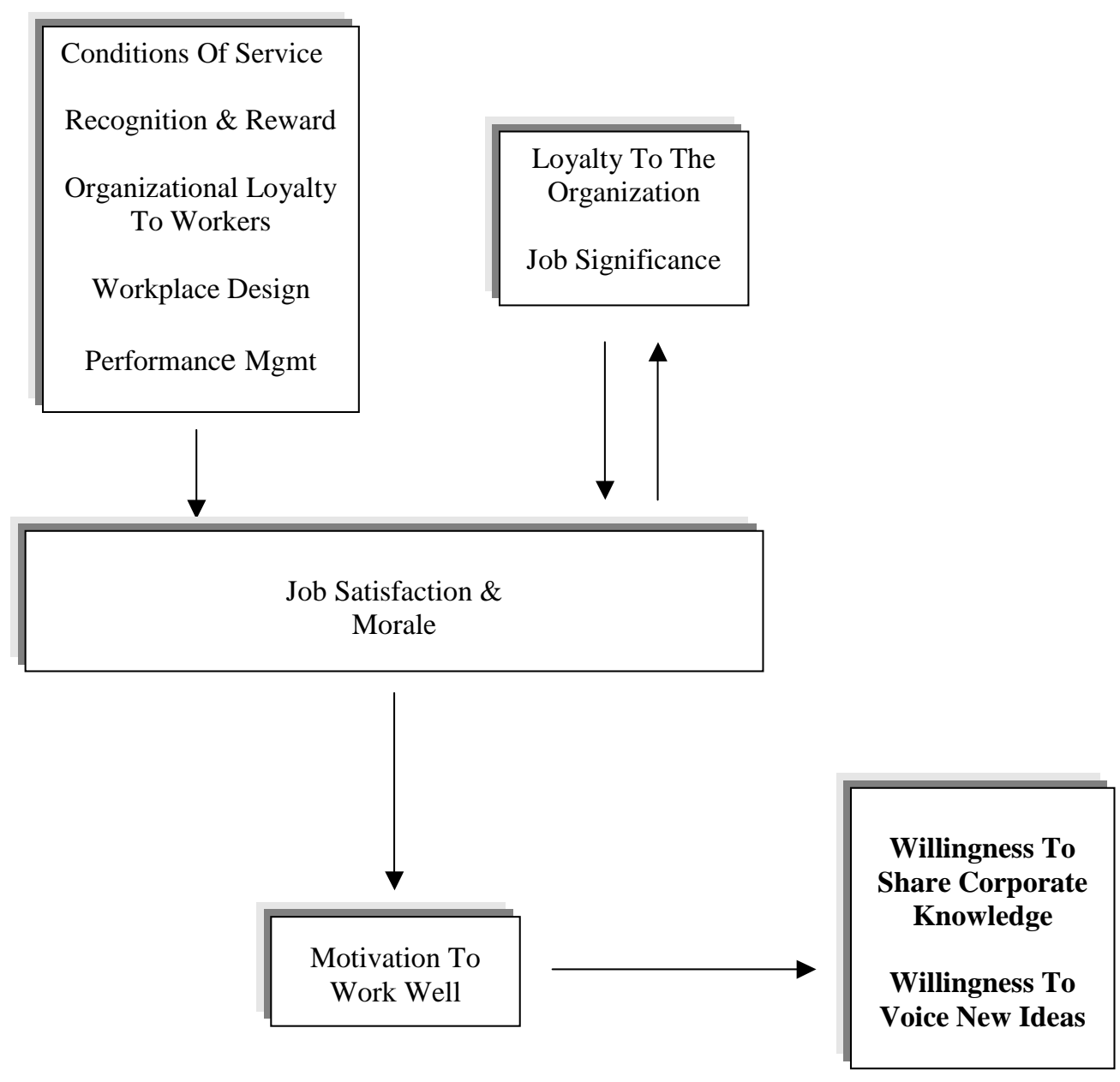

Figure 2 The Role of Job Satisfaction and Morale in Generative Learning

\section{The Role of Job Satisfaction and Morale in Organisational Learning}

Job satisfaction and the motivation to perform well at work is important in today's business climate not merely because of their links with high levels of work effectiveness - they are also important because the competitive advantage requires a 'knowledge edge' and this cannot be achieved unless employees are willing to engage in behaviours that will result in generative learning. These include the willingness to share corporate knowledge and the willingness to voice new ideas and engage in dialogue about new and innovative ways of working.

Figure 2 below illustrates the impact that factors associated with Job Satisfaction and Morale can have on these two elements that are vital to generative learning. The findings of the study reported in this paper suggest that Conditions of Service, Recognition \& Reward, Organizational Loyalty to Workers, Workplace Design, and Performance Management contribute directly to Job Satisfaction \& Morale. Loyalty To The Organization and Job Significance also contribute to Job Satisfaction \& Morale, but the relationship is recursive. For instance, higher levels of Job Satisfaction \& Morale would have positive impacts on Loyalty To The Organization and levels of Job Significance. Finally, Job Satisfaction \& Morale will im- 
Yet Another Role for Job Satisfaction and Work Motivation

pact on Motivation to Work Well, and this directly influence employees' Willingness To Share Corporate Knowledge and their Willingness to Voice New Ideas.

\section{Conclusion}

The research reported in this paper has pointed to various factors that enable generative learning, and a high level of job satisfaction/positive morale is one of these. The research data suggests that numerous elements influence job satisfaction and morale within the context of organizational learning: Conditions of Service, Recognition \& Reward, Organisational Loyalty To Workers, Workplace Design, Job Significance, Performance Management, and Loyalty To The Organisation. Employee perceptions of Organisational Loyalty to workers is likely to result in trust, which is another element that has been found by the ESLA team to be of importance in generative learning (Ali, et al. 2002). A full research report on the ESLA findings into social learning in the Australian Defence Organisation will be published in mid 2002.

\section{Bibliography}

Ali, I., Pascoe, C., Warne, L., Gori, R., Agostino, K., (2000) 'Enabling learning: A progress report on the Enterprise Social Learning Architecture Team', 5th International Command \& Control Research \& Technology Symposium, Canberra, 24 26 October 2000, [Proceedings on CD-ROM] U.S. Department of Defence-C3I \& Australian Department of DefenceDSTO

Ali, I., Warne, L., Agostino, K., Pascoe, C. (2001) 'Working and Learning Together: Social Learning In the Australian Defence Organisation', Informing Science Conference IS2001 - Bridging Diverse Disciplines Proceedings (CD-ROM), Krakow, Krakow University of Economics, Poland, June 19-22, 2001, ISSN 1535-0703.

Ali, I., Pascoe, C., Warne, L., 2002 "Interactions of organizational culture and collaboration in working and learning", The Journal of Education Technology and Society (in press)

Bednar, P. 2000. "A contextual integration of individual and organisational learning perspectives as part of IS analysis." Informing Science 3(3): 145-156.

Davenport, T. H. 1994. "Saving IT's Soul: Human-Centered Information Management.” Harvard Business Review 72: 119131.

Hackman, R. J. and G. R. Oldham 1980. Work Redesign., Addison-Wesley.

Mitchell, S. "Be Bold and Discover the Power of Praise" 2001, Simon \& Schuster.

Nevis, E. C., A. J. diBella and J. M. Gould 1995. "Understanding Organizations as Learning Systems." Sloan Management Review 36(2): 73-85.

Newton, K. and S. Magun 2001. Organizational Learning and Intellectual Capital. Doing Business in the Knowledge-Based Economy: Facts and Policy Challenges. L. A. Lefebvre, E. Lefebvre and P. Mohnen (Eds). Massachusetts, Kluwer Academic Publisher: 117-150.

Pascoe, C., Ali, I., Warne, L. 2002 Collaborative Knowledge Development, Dialogue, and Team Building: Findings from research into social learning in the Australian Defence Organization, Proceedings of the 2001 Australian Conference for Knowledge Management and Intelligent Decision Support, 10-11 December 2001, Monash University, Melbourne, in press.

Reichheld, F. 2001.“Leadership for Loyalty” Harvard Business Review 79(7): 76-84.

Richards, G. and S. C. Goh 1995. "Implementing Organizational Learning: Toward a Systemicatic Approach.” Optimum Autumn, 26(2): 10-14.

Tsang, E. W. K. 1997. “Organizational Learning and the Learning Organization.” Human Relations 50(1).

Vandeville, J. V. 2000. "Organisational learning through the collection of "lessons learned"." Informing Science 3(3): 127-133. 